\title{
DESIGN METHODOLOGY FOR LED LIGHTING SYSTEMS BASED ON PHOTO-ELECTRO-THERMAL INTERRELATIONSHIPS
}

\author{
Leandro Chies, Maicol F. de Melo, William D. Vizzotto, Rudimar Spannemberg Jr., Vitor C. Bender, \\ Marco A. Dalla Costa \\ Federal University of Santa Maria, Santa Maria - RS, Brasil \\ e-mail: leandro.chies@ifsc.edu.br, maicolmelo@gedre.ufsm.br
}

\begin{abstract}
This paper presents a design methodology for LED (Light-Emitting Diode) lighting systems based on photo-electro-thermal (PET) interrelationships. The proposed methodology uses only LED datasheet information, which makes experimental tests unnecessary to obtain the design parameters. The methodology allows identifying several design specifications, such as, luminous efficacy, heatsink thermal resistance, LED junction temperature and forward current, essential aspects to produce a satisfactory lighting system. Thus, it is possible to define the lighting system features based on standards requirements to obtain the desired system results. Initially, a review of several PET theories is presented, and a new mathematical analysis is performed, in order to highlight the main contributions of the methodology. An LED bulb lamp design is presented to exemplify the methodology. Finally, experimental tests with the proposed LED lamp resulted in a luminous flux of $1271 \mathrm{~lm}$, with a luminous efficacy of $112 \mathrm{~lm} / \mathrm{W}$, and LED junction temperature of $79.67^{\circ} \mathrm{C}$. The errors between calculated and measured luminous flux, luminous efficacy and LED junction temperature were $3.70 \%, 1.88 \%$, and $3.85 \%$, respectively. These results validate the proposed methodology.
\end{abstract}

Keywords - Design Methodology, Light-Emitting Diodes, Photo-Electro-Thermal Theory.

\section{INTRODUCTION}

Nowadays the search for more efficient and environmentally friendly lighting systems presents a great social acclaim. In this scenario, the more traditional lighting technologies, such as incandescent and compact fluorescent lamps (CFL), are conceding space for new lighting possibilities, like as LED-based lamps. LEDs present lifetime up to $100,000 \mathrm{~h}$, luminous efficacy higher than $150 \mathrm{~lm} / \mathrm{W}$, high color rendering index, robustness, driver simplicity and other advantages [1].

In addition, LEDs have great potential to save energy, the United States Department of Energy (DOE) estimates that the growth of solid state lighting (SSL) may be responsible for saving between 261 and 395 terawatt-hour in 2030 compared to a no SSL scenario, only in United States territory [2].

Manuscript received 27/11/2017. First revision 28/01/2018. Accepted for publication 05/03/2018, by recommendation of Editor Marcello Mezaroba.
However, a proper design is required during the LED lamp conception, and it requires a modeling that integrates photometrical, electrical and thermal (PET) parameters, once these interrelations have influence in the LEDs' features [3][8]. Thus, the hard task in LED lamp conception is the PET design, which can guarantee a long lifetime with a desired luminous efficacy and low cost.

The literature presents many PET theories. For example, [9]-[12] propose the luminous flux determination. In [9], the luminous flux is estimated considering two functions: relative emitted flux vs. LED junction temperature and relative emitted flux vs. forward current. Reference [10] performs an improvement over [9], estimating the junction temperature by ambient temperature, electrical and thermal parameters. Moreover, algorithms to maximize the luminous flux for an optimal forward current, or to minimize the heatsink size, were also proposed. The work proposed in [11] estimates the luminous flux through the relation of luminous efficacy and LED power, where electrical and thermal parameters are used to estimate the luminous efficacy. Furthermore, it also presents a method to achieve the maximum luminous flux at an optimal power. Reference [12] improves the former theory, it uses a variable $k_{h}$ coefficient (percentage of electrical power transformed in heat). Nevertheless, a difficult factor to use PET theory is that most of these theories require experimental tests in expensive equipments to obtain the PET theory parameters, for example an integrating sphere. References [13] and [14] presented a strategy to obtain the PET theory parameters trough the LED datasheet information.

In order to improve the state of art in PET theory, this paper proposes a methodology to design LED lighting systems based only on LEDs datasheet information, without any experimental or simulation tests. This methodology consists in three steps, organized in the following sections: PET parameters determination, Section II; equation of LED lighting system specifications, Section III; and graphical analysis using a design example, Section IV. Section V presents the experimental results obtained for the design example, while Section VI shows the main paper conclusions.

\section{PHOTO-ELECTRO-THERMAL PARAMETERS ACHIEVEMENT BASED ON LED DATASHEET}

The PET theory has been widely explored in the literature, which is based on the following equations, presented by [11]: 


$$
\begin{gathered}
\phi_{V}=N_{l d} P_{l d} E \\
E=E_{0}\left[1+k_{e}\left(T_{a}-T_{0}\right)+k_{e} k_{h} P_{l d}\left(N_{l d} R_{h s}+R_{j c}\right)\right] \\
\phi_{V}=N_{l d} E_{0}\left\{\left[1+k_{e}\left(T_{a}-T_{0}\right)\right] P_{l d}+\left[k_{e} K_{h}\left(N_{l d} R_{h s}+R_{j c}\right)\right] P_{l d}{ }^{2}\right\} .
\end{gathered}
$$

Equation (1) calculates the luminous flux of the system by multiplying the number of LEDs $\left(N_{l d}\right)$ by the LED power $\left(P_{l d}\right)$ and efficacy $(E)$. Replacing (2), that presents the luminous efficacy, in (1), it results in a complete expression for the luminous flux estimative (3). Table I presents the general PET parameters used in this study.

\section{TABLE I}

General PET Parameters

\begin{tabular}{ccc}
\hline Symbol & Meaning & Unity \\
\hline $\mathrm{N}_{\mathrm{ld}}$ & LEDs quantity & - \\
\hline $\mathrm{E}$ & Luminous efficacy & $1 \mathrm{~m} / \mathrm{W}$ \\
\hline$\phi_{\mathrm{v}}$ & Luminous flux & $\mathrm{lm}$ \\
\hline $\mathrm{P}_{\mathrm{ld}}$ & LED electrical power & $\mathrm{W}$ \\
\hline $\mathrm{E}_{0}$ & Reference efficacy in $T_{0}$ & $1 \mathrm{~m} / \mathrm{W}$ \\
\hline $\mathrm{T}_{0}$ & Reference temperature & ${ }^{\circ} \mathrm{C}$ \\
\hline $\mathrm{T}_{\mathrm{a}}$ & Ambient temperature & ${ }^{\circ} \mathrm{C}$ \\
\hline $\mathrm{V}_{\mathrm{e}}$ & Negative coefficient that represents the E reducing & $1 /{ }^{\circ} \mathrm{C}$ \\
\hline $\mathrm{T}_{\mathrm{j}}$ & rate with $\mathrm{T}_{\mathrm{j}}$ increase. & ${ }^{\circ} \mathrm{C}$ \\
\hline $\mathrm{k}_{\mathrm{h}}$ & LED electrical power percentage transformed in heat & ${ }^{\circ} \%$ \\
\hline $\mathrm{R}_{\mathrm{jc}}$ & Junction to case thermal resistance & ${ }^{\circ} \mathrm{C} / \mathrm{W}$ \\
\hline $\mathrm{R}_{\mathrm{hs}}$ & Heatsink to ambient thermal resistance & ${ }^{\circ} \mathrm{C} / \mathrm{W}$ \\
\hline
\end{tabular}

The improvement proposed in this work, compared to other theories presented in the literature, is that the $\phi_{v}$ estimation is achieved using a variable $E_{0}$ jointly with a $k_{h}$ estimative performed through LED datasheet. Besides, $P_{l d}$ is related to thermal parameters and LED forward current, which is performed in Section II.C.

\section{A. Variable Reference Efficacy $\left(E_{0}\right)$}

The LED luminous efficacy depends on the LED junction temperature and forward current $\left(I_{f}\right)$. One of the main parameters used to determine $\phi_{v}$ is $E_{0}$. In [11], $E_{0}$ is held constant during $P_{l d}$ and $\phi_{v}$ variations. However, $E_{0}$ changes according to $I_{f}$ at $T_{0}$, because of the droop effect [15]. Thus, the parameter $E_{0}$ can be represented as $I_{f}$ dependent, $E_{0}\left(I_{f}\right)$, which can be modeled through the LED datasheet information, where the LED manufacturer shows graphically a curve of $\phi_{v}$ vs. $I_{f}$ and another curve of forward voltage $\left(V_{f}\right)$ vs. $I_{f}$. Both curves are obtained under $T_{0}$.

The process to obtain $E_{0}\left(I_{f}\right)$ depends on modeling $\phi_{v}$ and $V_{f}$ as function of $I_{f}$ at $T_{0}$, as shown in Figures 1 and 2, respectively. These curves are approximated by a polynomial interpolation, where $p_{\phi}\left(I_{f}\right)$ represents the polynomial generated by $\phi_{v}$ vs. $I_{f}$ and $p_{v}\left(I_{f}\right)$ by $V_{f}$ vs. $I_{f}$. Thus, $E_{0}\left(I_{f}\right)$ can be given by:

$$
E_{0}\left(I_{f}\right)=\frac{p_{\phi}\left(I_{f}\right) \phi_{0}}{I_{f} p_{v}\left(I_{f}\right)}
$$

where $\phi_{0}$ is the reference flux used to normalize the $\phi_{v}$ vs. $I_{f}$, according to Figure 1.
Polynomial degree may vary depending on the desired accuracy level. A third degree polynomial is used in this case, enabling a satisfactory approximation model in the whole range of $I_{f}$. The graphs presented in Figures 1 and 2 and the respective polynomial approximation refer to Luxeon 3535L (MxA8-PW40-4000K) LED model. The polynomials coefficients of $p_{\phi}\left(I_{f}\right)$ and $p_{v}\left(I_{f}\right)$ are, respectively, $d_{0}, d_{1}, d_{2}$ and $d_{3}$, according to (5) and $v_{0}, v_{1}, v_{2}$ and $v_{3}$, according to (6)(6). Section II.D describes the values of these coefficients. Figure 3 shows the variation of $E_{0}$ vs. $I_{f}$, for the chosen LED model.

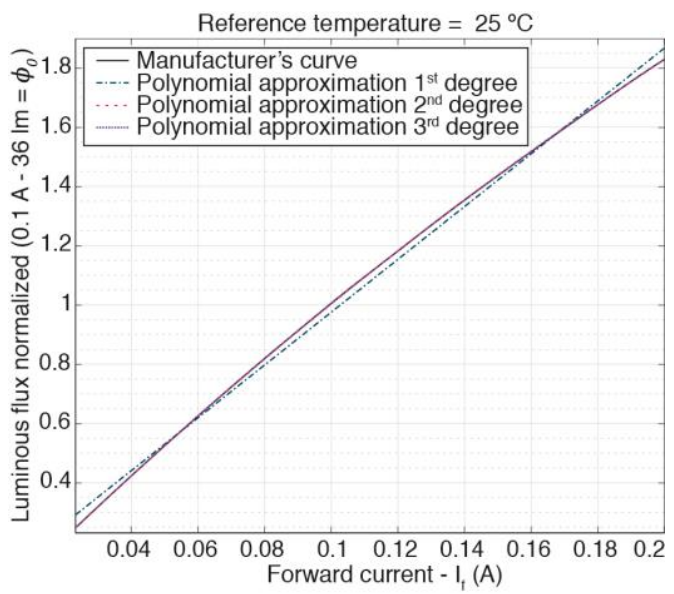

Fig. 1. Normalized $\phi_{v}$ as function of $I_{f}$ (adapted from [16]).

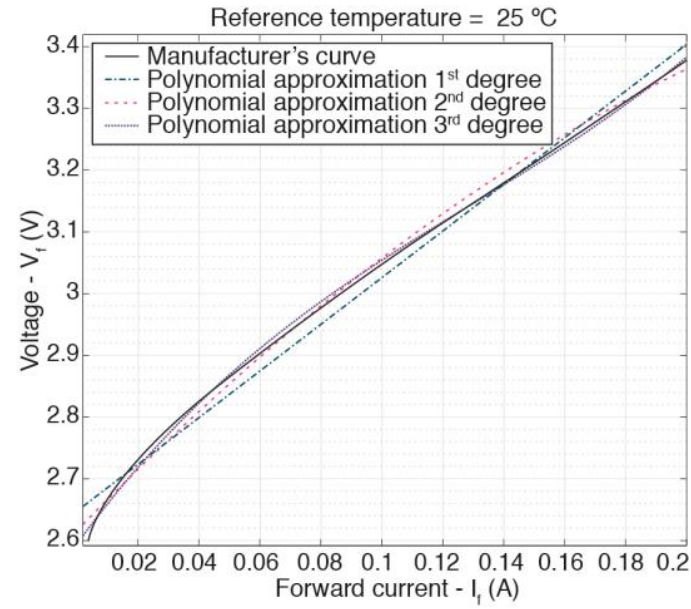

Fig. 2. Vf as function of If (adapted from [16]).

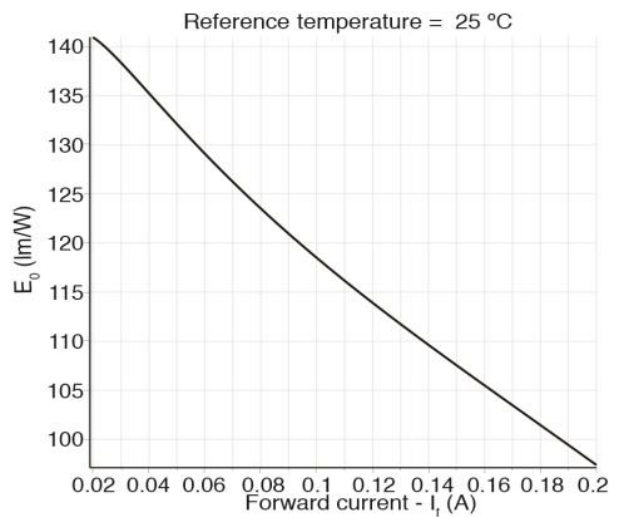

Fig. 3. E0 variation as If function for LED Luxeon $3535 \mathrm{~L}$. 


$$
\begin{aligned}
& p_{\phi}\left(l_{f}\right)=\left(d_{3} l_{f}^{3}+d_{2} l_{f}^{2}+d_{1} l_{f}+d_{0}\right) \\
& p_{v}\left(l_{f}\right)=\left(v_{3} l_{f}^{3}+v_{2} l_{f} 2+v_{1} l_{f}+v_{0}\right)
\end{aligned}
$$

\section{B. $k_{h}$ Coefficient Estimative}

The coefficient $k_{h}$ relates the percentage of electrical power transformed in heat. The methods to obtain $k_{h}$ are empirical value estimation, as in [10], or performing experimental tests in one integrating sphere, as in [11] and [12]. However, these methods require expensive equipments. Therefore, a method to determine the $k_{h}$ coefficient without experimental test is highly desirable, saving time and cost in the design. Thus, this study presents a method to obtain the coefficient $k_{h}$ through the LED datasheet data, avoiding laboratory tests.

It is estimated by spectral power distribution $\emptyset_{r}(\lambda)$ (SPD) at temperature $T_{0}$ provided in the LED datasheet, which is normalized and represented by $\varnothing_{r n}(\lambda)$. As the white LED light radiant spectrum is predominantly in the visible wavelength range, the lumen definition (7) originates a modified lumen definition (8). The modified lumen definition allows determining the coefficient $k_{n}$, which reverses the radiant spectrum normalization coefficient. This coefficient is isolated in (8), resulting in (9), where $\phi_{v}$ is the total luminous flux at test current (usually the same as $\phi_{0}$ ), obtained from the LED datasheet. Once the 1931 CIE photopic luminosity function, $V(\lambda)$, can be found in [17], the LED manufacturer datasheet presents the additional necessary data to find $k_{n}$. The $k_{h}$ can be obtained substituting (10) and (11) in (12), since (10) defines the total radiant power $\phi_{r}$, and (11) defines the thermal power $P_{h}$, which represents the amount of LED electrical power turned into radiant energy and into heat energy, respectively.

Thus, in order to determine $k_{h}$, the normalized values of radiant SPD for each wavelength of the observer $V(\lambda)$ must be obtained, considering the photopic vision. The LED datasheet presents some wavelength corresponding values of the SPD in graphic form, and then the radiant SPD can be approximated by fitting three Gaussian functions, according to (13) where $a_{i}$ is the amplitude, $b_{i}$ is the centroid (location), $c_{i}$ is related to the peak width of a Gaussian function. Section II.D describes these coefficients' values. Figure 4 presents the approximation results for Luxeon 3535L.

$$
\begin{gathered}
\phi_{\mathrm{V}}=683 \int \phi_{\mathrm{r}}(\lambda) \mathrm{V}(\lambda) \mathrm{d} \lambda \\
\phi_{\mathrm{V}}=683 \int \mathrm{K}_{\mathrm{n}} \phi_{\mathrm{rn}}(\lambda) \mathrm{V}(\lambda) \mathrm{d} \lambda \\
\mathrm{k}_{\mathrm{n}}=\frac{\phi_{\mathrm{V}}}{683 \int \phi_{\mathrm{rn}}(\lambda) \mathrm{V}(\lambda) \mathrm{d} \lambda} \\
\phi_{\mathrm{r}}=\mathrm{k}_{\mathrm{n}} \int \phi_{\mathrm{rn}}(\lambda) \\
\mathrm{P}_{\mathrm{h}}=\mathrm{P}_{\mathrm{ld}}-\phi_{\mathrm{r}} \\
\mathrm{k}_{\mathrm{h}}=\frac{\mathrm{P}_{\mathrm{h}}}{\mathrm{P}_{\mathrm{ld}}}
\end{gathered}
$$

$$
\begin{aligned}
& \phi_{\mathrm{rn}}=\mathrm{a}_{1}\left(\exp \left(-\left(\left(\mathrm{x}-\mathrm{b}_{1}\right) / \mathrm{c}_{1}\right)^{2}\right)\right)+ \\
& \mathrm{a}_{2}\left(\exp \left(-\left(\left(\mathrm{x}-\mathrm{b}_{2}\right) / \mathrm{c}_{2}\right)^{2}\right)\right)+\mathrm{a}_{3}\left(\exp \left(-\left(\left(\mathrm{x}-\mathrm{b}_{3}\right) / \mathrm{c}_{3}\right)^{2}\right)\right)
\end{aligned}
$$

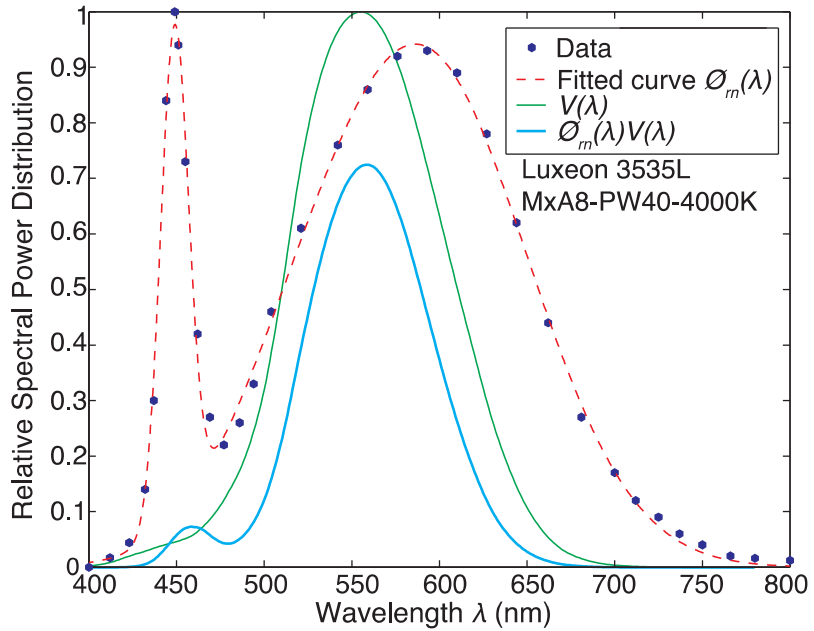

Fig. 4. Radiant spectral approximation for Gaussian functions under $\mathrm{T}_{\mathrm{a}}=25^{\circ} \mathrm{C}$, and $1931 \mathrm{CIE}$ photopic luminosity function $\mathrm{V}(\lambda)$.

It is important to highlight that, physically, the $k_{h}$ coefficient varies according to $T_{j}$ and $I_{f}$. However, this effect can be also represented by the $E_{0}\left(I_{f}\right)$ variation. Although, in this methodology, $k_{h}$ is considered as constant and its variation is intrinsic to the $E_{0}$ variable.

\section{Variable Electrical Power $\left(P_{l d}\right)$}

The LED forward voltage $\left(V_{f}\right)$ decreases quasi-linearly with $T_{j}$ increase [18]. Therefore, (6) can be rewritten to take into account $T_{j}$ variation, as shown in (14) [10]. Where $k_{v}$ is a negative coefficient that represents the ratio of the $V_{f}$ variation with $T_{j}$, presented directly or graphically in the LED datasheet. By inserting (15), found by [11], in (14), and solving for $V_{f}$, it is possible to get the voltage as current and thermal parameters function, according to (16). Multiplying (16) by $I_{f}$, it results the electrical power (17).

$$
\begin{gathered}
V_{f}=p_{v}\left(l_{f}\right)+k_{v}\left(T_{j}-T_{0}\right) \text { for } T_{j}>T_{0} \\
T_{j}=T_{a}+k_{h} V_{f} I_{f}\left(N_{l d} R_{h s}+R_{j c}\right) \\
V_{f}\left(l_{f}\right)=\frac{p_{v}\left(I_{f}\right)+k_{v}\left(T_{a}-T_{0}\right)}{1-k_{v} k_{h} l_{f}\left(N_{l d} R_{h s}+R_{j c}\right)} \\
P_{l d}\left(l_{f}\right)=\frac{p_{v}\left(l_{f}\right)+k_{v}\left(T_{a}-T_{0}\right)}{1-k_{v} k_{h} l_{f}\left(N_{l d} R_{h s}+R_{j c}\right)} l_{f}
\end{gathered}
$$

\section{Technical Data}

As previously cited, this work employs the LED Luxeon 3535L, model MxA8-PW40 4000K. Table II shows the parameters obtained directly from datasheet and indirectly, through the procedures presented in the former sections. 
TABLE II

Parameters Obtained From Luxeon 3535L Datasheet

\begin{tabular}{|c|c|c|}
\hline Method & Symbol & Value \\
\hline \multirow{19}{*}{$\begin{array}{l}\text { Indirectly obtained } \\
\text { Parameters }\end{array}$} & $a_{1}$ & 0.8866 \\
\hline & $b_{1}$ & 448.9 \\
\hline & $c_{1}$ & 11.29 \\
\hline & $a_{2}$ & 0.9184 \\
\hline & $b_{2}$ & 590.6 \\
\hline & $c_{2}$ & 84.62 \\
\hline & $a_{3}$ & 0.1236 \\
\hline & $b_{3}$ & 514 \\
\hline & $c_{3}$ & 57.56 \\
\hline & $d_{3}$ & 11.5556 \\
\hline & $d_{2}$ & -12.8667 \\
\hline & $d_{1}$ & 11.3053 \\
\hline & $d_{0}$ & -0.0082 \\
\hline & $v_{3}$ & 74.5589 \\
\hline & $v_{2}$ & -28.8816 \\
\hline & $v_{l}$ & 6.7364 \\
\hline & $v_{0}$ & 2.5946 \\
\hline & $k_{e}$ & $-0.0015919^{1}$ \\
\hline & $k_{h}$ & 0.54 \\
\hline \multirow{4}{*}{$\begin{array}{l}\text { Directly obtained } \\
\text { Parameters }\end{array}$} & $\emptyset_{0}(\operatorname{lm})$ & 36 \\
\hline & $R_{j c}\left({ }^{\circ} \mathrm{C} / W\right)$ & 33.33 \\
\hline & $k_{v}\left(m V /{ }^{\circ} \mathrm{C}\right)$ & -3 \\
\hline & $T_{0}\left({ }^{\circ} \mathrm{C}\right)$ & 25 \\
\hline
\end{tabular}

\section{E. Estimated Luminous Flux With Variable $E_{0}$}

The estimated luminous flux with variable efficacy, $E_{0}\left(I_{f}\right)$, presented in (18), has been validated through an LED bulb lamp tested in an integrating sphere $(200 \mathrm{~cm}$ diameter $)$ of Inventfine ${ }^{\mathrm{TM}}$, according to Figure 5. The proposed theory with variable $E_{0}\left(I_{f}\right)$ keeps the trend of the measured flux, which makes clear an improvement, once for fixed $E_{0}$ the curve behavior would be linear.

$$
\phi_{V}\left(l_{f}\right)=N_{l d} E_{0}\left(l_{f}\right)\left\{\begin{array}{l}
{\left[1+k_{e}\left(T_{a}-T_{0}\right)\right] P_{d d}\left(l_{f}\right)+} \\
{\left[k_{e} k_{h}\left(N_{l d} R_{h s}+R_{j c}\right)\right]\left(P_{d d}\left(l_{f}\right)\right)^{2}}
\end{array}\right\} .
$$

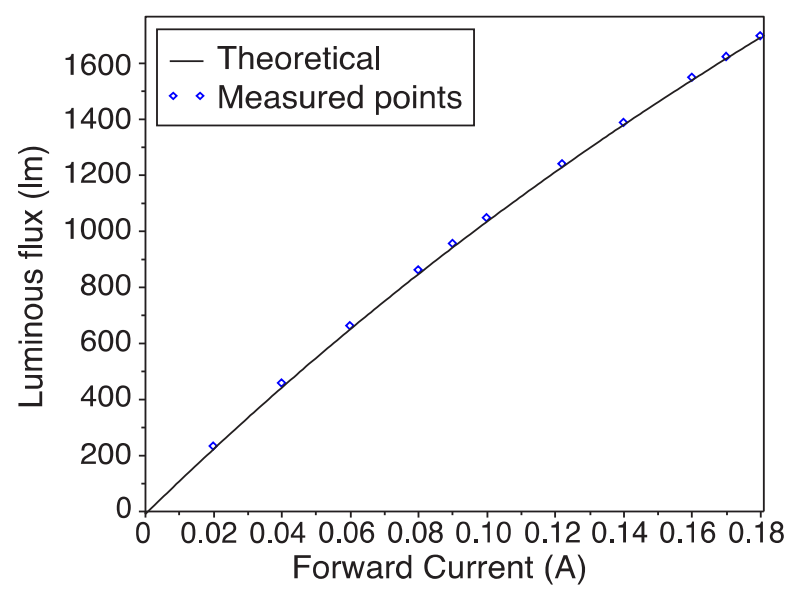

Fig. 5. Comparison between theoretical and experimental luminous flux for an LED bulb lamp with $\mathrm{R}_{\mathrm{hs}}=0.73{ }^{\circ} \mathrm{C} / \mathrm{W}$.

This section presented a procedure to obtain the PET parameters necessary to start a LED system design.

${ }^{1}$ Linearization between $25^{\circ} \mathrm{C}$ and $105^{\circ} \mathrm{C}$.
However, a second step is necessary, the LED lighting system specifications, which is addressed in Section III.

\section{LED LIGHTING SYSTEM SPECIFICATIONS}

Three important specifications for a suitable LED lighting system design are: the heatsink thermal resistance, the LED junction temperature, and the overall system luminous efficacy. These specifications are defined considering LEDs' quantity and LEDs' forward current.

Thus, since the designer knows these specifications, it is possible to perform different designs with distinct targets. For example, the focus can be the lamp lifetime, the system luminous efficacy or even the system cost. Another important possibility is to visualize different lighting systems, as different LEDs' quantity or LEDs' current, maintaining same performance and quality requirements.

Therefore, a complete design of a LED lighting system can be performed satisfactorily, where $E, T_{j}, N_{l d}, I_{f}$, total luminous flux, electrical power consumption, lifetime and system cost can be previously estimated.

In order to determine these three specifications, the following mathematical procedure is proposed:

1) Heatsink thermal resistance $\left(R_{h s}\right)$ : The $R_{h s}$ definition is performed inserting (4) and (17) into (18), resulting in:

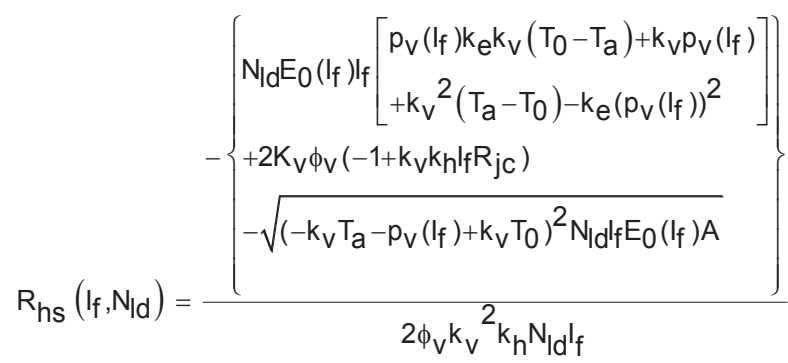

where,

$A=N_{l d} E_{0}\left(l_{f}\right) I_{f}\left(k_{v}{ }^{2}-2 k_{e} k_{v} p_{v}(I f)+k_{e}{ }^{2}\left(p_{v}\left(l_{f}\right)\right)^{2}\right)+4 k_{v} \phi_{v} k_{e}$

2) LED junction temperature $\left(T_{j}\right)$ : The LED junction temperature $T_{j}$ is estimated inserting (16) into (15) and $R_{h s}$ is replaced according to (19), resulting in:

$$
\begin{aligned}
& T_{j}\left(I_{f}, N_{l d}\right)=T_{a}+\left(R_{j c}+R_{h s}\left(I_{f}, N_{l d}\right) N_{l d}\right) k_{h} \\
& \left(\frac{p_{v}\left(I_{f}\right)+k_{v}\left(T_{a}-T_{0}\right)}{1-k_{v} k_{h} l_{f}\left(N_{l d} R_{h s}\left(I_{f}, N_{l d}\right)+R_{j c}\right)} I_{f}\right) .
\end{aligned}
$$

The assumption of $k_{h}$ constant to estimate $T_{j}$ is an approximation. The error caused by this approximation is not significant, due the small temperature ranges of the system. However, if higher accuracy is desired, the variable $k_{h}$ parameter can be obtained as presented in [12], which demands experimental tests.

3) System luminous efficacy (E): The system luminous efficacy $E$ is calculated inserting (17) into (2) and $R_{h s}$ is replaced according to (19), resulting in: 


$$
E\left(I_{f}, N_{l d}\right)=E_{0}\left(I_{f}\right)\left[\begin{array}{l}
1+k_{e}\left(T_{a}-T_{0}\right)+k_{e} k_{h}\left(R_{j c}+R_{h s}\left(I_{f}, N_{l d}\right) N_{l d}\right) \\
\left(\begin{array}{c}
p_{v}\left(I_{f}\right)+k_{v}\left(T_{a}-T_{0}\right) \\
1-k_{v} k_{h f} I_{l d}\left(N_{l d} R_{h s}\left(I_{f}, N_{l d}\right)+R_{j c}\right)
\end{array}\right)
\end{array}\right] .
$$

In this methodology stage, it is possible to perform a graphical analysis and predict the design results. Figure 6 shows the three parameters $\left(R_{h s}, T_{j}, E\right)$ variation as $I_{f}$ function considering just one LED. This estimative considers $T_{a}$ of $30^{\circ} \mathrm{C}$ and different possibilities for the luminous fluxes, distinguished by different line colors. The ordinates axis represents, simultaneously, the $R_{h s}, T_{j}$ and $E$.

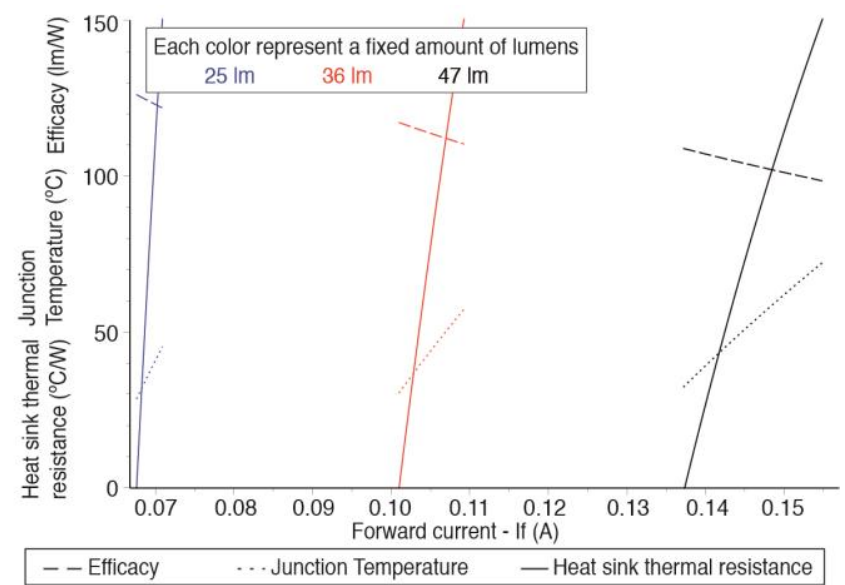

Fig. 6. PET parameters $\left(R_{h s}, T_{j}, E\right)$ variation as forward current function (Luxeon $3535 \mathrm{~L}$ ).

\section{A. Proposed Methodology Resume}

Aiming to resume the proposed methodology, Figure 7 presents a methodology flowchart. The first step is to obtain the parameters from the LED datasheet (Table II). After that, the coefficients are calculated to be used in the system specifications (data process - Section III). Finally, the results are graphically presented (design space), enabling the designer to define the system characteristics.

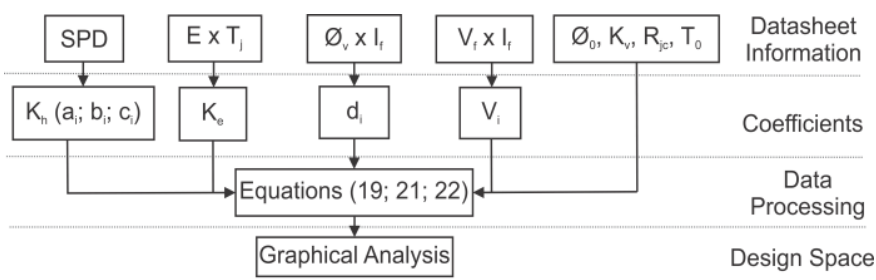

Fig. 7. Methodology flowchart.

\section{DESIGN EXAMPLE}

An LED bulb lamp that employs the LED Luxeon 3535L, model MxA8-PW40-4000K, is used as a methodology design example. This lamp must comply with the requirements present by 389 INMETRO ordinance and Energy Star requirements [19]-[21] besides obtaining the energetic efficiency Procel Seal. Therefore, LED lamp must provide a luminous flux of $1100 \mathrm{~lm}$ with a luminous efficacy higher than $80 \mathrm{~lm} / \mathrm{W}$. Table III presents the main requirements that the LED lamp must comply.
TABLE III

LED Bulb Lamp Requirements

\begin{tabular}{cc}
\hline Requirement & Value \\
\hline Minimum Efficacy & $80 \mathrm{~lm} / \mathrm{W}$ \\
\hline Minimum Lifetime & $25000 \mathrm{~h}$ \\
\hline Maximum variation of chromaticity coordinates & 0.007 \\
\hline Luminous Flux to replace a 75W incandescent lamp & $1100 \mathrm{~lm}$ \\
\hline
\end{tabular}

Considering the diffuser efficiency equal to $90 \%$ and the electronic driver efficiency equal to $85 \%$, according to Figure 8, the LEDs must provide approximately a luminous flux of $1223 \mathrm{~lm}$ and a minimum luminous efficacy of 110 $\mathrm{lm} / \mathrm{W}$, aiming to result in a lamp with luminous efficacy of $85 \mathrm{~lm} / \mathrm{W}$ and a total luminous flux of $1100 \mathrm{~lm}$.

Other important parameter is the LED lifetime, which is related to $T_{j}$ and $I_{f}$. For this LED model, $T_{j}$ must be below $105^{\circ} \mathrm{C}$ and the maximum $I_{f}$ is $150 \mathrm{~mA}$, to guarantee a lifetime of 25,000 hours, according to lumen maintenance and reliability LED LM-80 manufacture report [22]. Furthermore, considering these values, the chromaticity change is 0.0054 after 6,000 hours tests, which is in conformity with IES-LM-80, approved method for measuring lumen maintenance of LED light sources. Once defined the parameters and performance requirements, a design space for the LED bulb lamp is generated, as shown in Figure 6. It is important to mention that the bulb presents a preset $R_{h s}=7.7^{\circ} \mathrm{C} / \mathrm{W}$. Thus, there are two parameters to be analyzed, $E$ and $T_{j}$, which are related to $I_{f}$ and $N_{l d}$. Table II presented the used parameters to generate the design space. The maximum lamp $N_{l d}$ possible is 50 , considering physical space of the lamp bulb.

Figure 9 presents that for $E \geq 110 \mathrm{~lm} / \mathrm{W}$ the minimum $N_{l d}$ is 41 . Therefore, for achieving the required $E$, considering the space limitation, it is feasible an LED bulb lamp with $N_{l d}$ between 41 and 50 . Regarding $T_{j}$, for the $N_{l d}$ possibilities, all range is in agreement with the requirement of $T_{j}$ below than $105^{\circ} \mathrm{C}$, according to Figure 10 . Then, it was defined an LED bulb lamp with 41 LEDs connected in series, supplied by a forward current $I_{f}$ of $94 \mathrm{~mA}$.

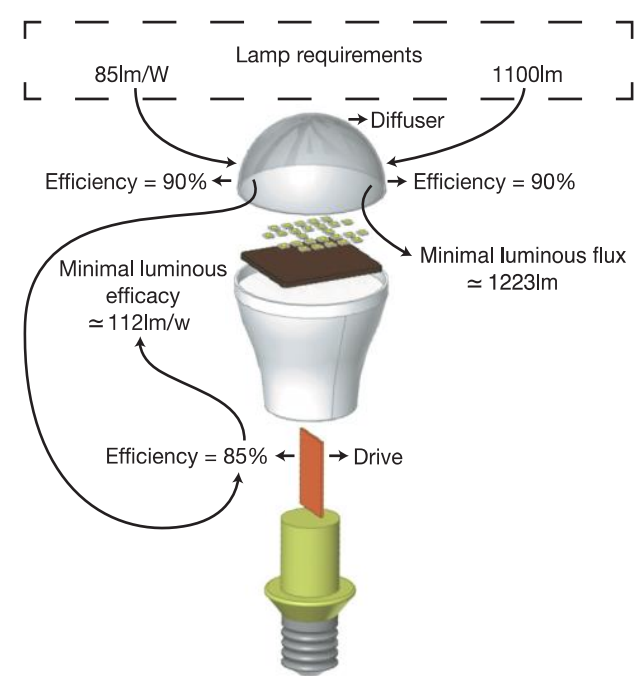

Fig. 8. LED bulb lamp: requirements and losses. 


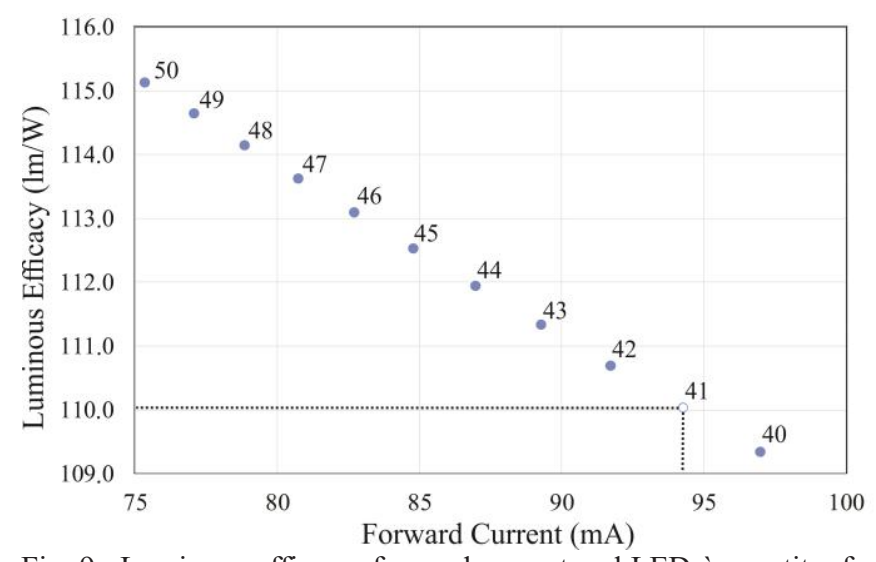

Fig. 9. Luminous efficacy, forward current and LEDs` quantity, for a LED lamp with $1100 \mathrm{~lm}$.

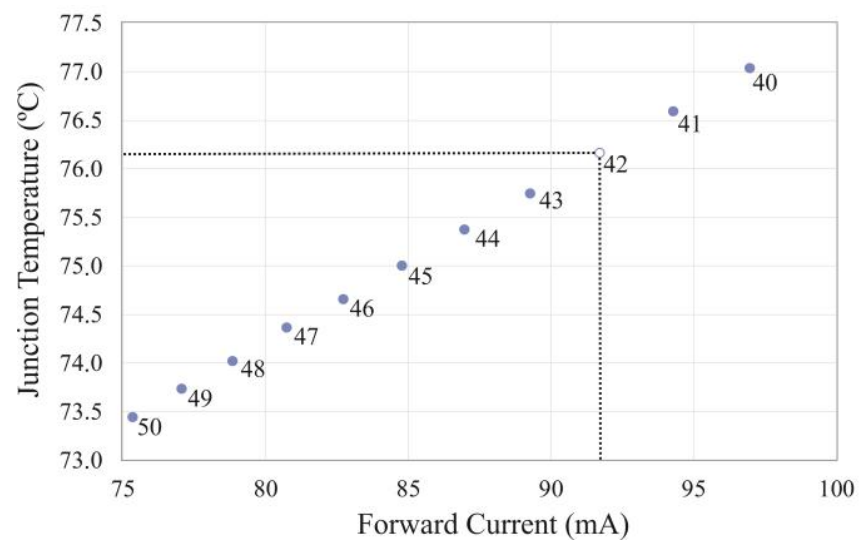

Fig. 10. Junction temperature, forward current and LED's quantity, for a LED lamp with $1100 \mathrm{~lm}$.

\section{EXPERIMENTAL RESULTS}

The results obtained in the design example were used in order to validate the previously analysis, an LED bulb lamp $\left(\mathrm{R}_{\mathrm{hs}}=7.77^{\circ} \mathrm{C} / \mathrm{W}\right)$ composed by 41 LEDs, with $I_{f}$ equal to $94 \mathrm{~mA}$ was built and experimentally verified. With these specifications, a luminous efficacy of $110 \mathrm{~lm} / \mathrm{W}$, a total luminous flux of $1223 \mathrm{~lm}$ and a junction temperature of $76.6^{\circ} \mathrm{C}$ are expected, which are according to the design example presented in Section IV.

Experimental tests were performed using an integrating sphere with a spectrophotocolorimeter. The junction temperature was estimated by measuring the LED pad temperature with a k-type thermocouple, using the power applied and the resistance $R_{j c}$, as in [23]. At least two measurements were performed, at 15 minutes intervals, checking if the variation between the measurements of voltage and luminous flux were smaller than $0.5 \%$. This ensures the system stabilization, as described in [24].

Figure 11 represents a comparative graphic between theoretical and experimental $\phi_{v}$ related to $I_{f}$, which shows a high accuracy level. A small deviation between theoretical and experimental values are observed for high forward current values. This effect occurs due the approximations considered in some parameters, e.g. $k_{h}$ and $k_{v}$ coefficients, and variations in thermal resistances, which are more significant under high currents.

Figure 12 presents thermography image for defined $I_{f}$, which shows the temperature distribution among the LEDs. Table IV shows theoretical and experimental results and the respective errors, according to (23). As can be observed, the experimental results validated the proposed methodology, presenting a luminous flux of $\phi_{v}=1271 \mathrm{~lm}$ with $E=112 \mathrm{~lm} / \mathrm{W}$.

$$
\operatorname{error}(\%)=\frac{(\text { measured }- \text { calculated })}{\text { measured }} * 100
$$

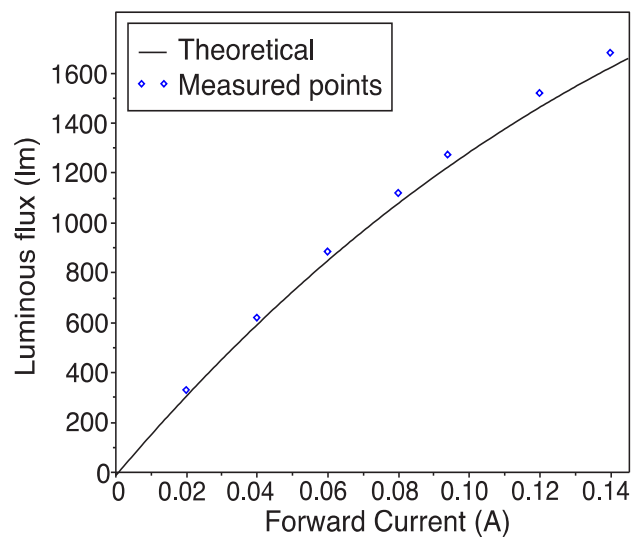

Fig. 11. Theoretical and experimental $\emptyset_{\mathrm{v}}$ vs. If for the lamp.

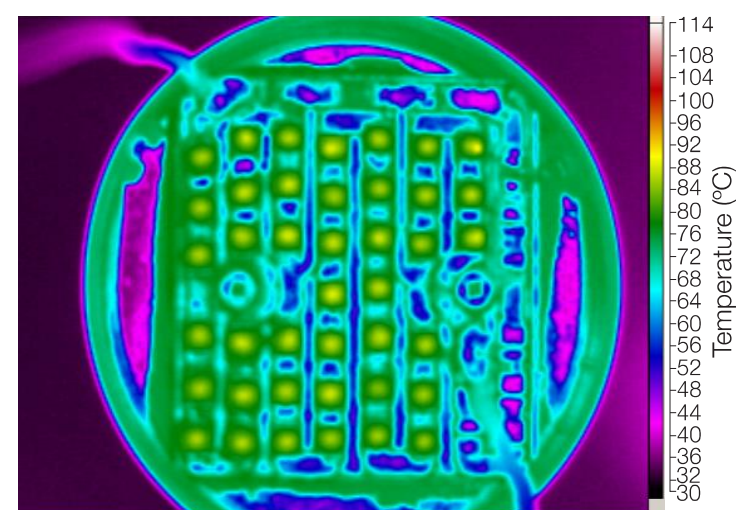

Fig. 12. Thermography image of bulb lamp for $\mathrm{I}_{\mathrm{f}}$ equal to $94 \mathrm{~mA}$.

TABLE IV

Comparison Between PET Methodology Design and Experimental Results

\begin{tabular}{|c|c|c|c|c|c|c|c|c|c|c|c|c|}
\hline \multirow{2}{*}{ 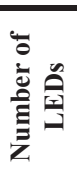 } & \multirow{2}{*}{ 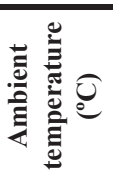 } & \multirow[b]{2}{*}{ 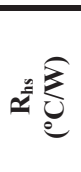 } & \multirow{2}{*}{ 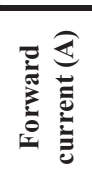 } & \multicolumn{3}{|c|}{ Luminous flux (Im) } & \multicolumn{3}{|c|}{ Luminous efficacy $(\mathrm{Im} / \mathrm{W})$} & \multicolumn{3}{|c|}{ Junction temperature $\left({ }^{\circ} \mathrm{C}\right)$} \\
\hline & & & & calculated & measured & $\begin{array}{c}\text { error } \\
\text { (\%) }\end{array}$ & calculated & measured & $\begin{array}{c}\text { error } \\
\text { (\%) }\end{array}$ & calculated & estimated & $\begin{array}{c}\text { error } \\
\text { (\%) }\end{array}$ \\
\hline 41 & 24.3 & 7.77 & 0.094 & 1224.65 & 1271.7 & 3.70 & 110.25 & 112.36 & 1.88 & 76.6 & 79.67 & 3.85 \\
\hline
\end{tabular}




\section{CONCLUSION}

This paper presented an alternative to obtain the PET parameters that avoids any experimental test or simulation to perform LED lighting system design. The PET theory allows the designer previously define the system specifications. The main improvements of the proposed methodology are obtaining $k_{h}$ coefficient without experimental tests, based only on datasheet information; definition of a dynamic $E_{0}$, which is dependent on forward current; and equations optimization to obtain the LED lighting system specifications.

An LED bulb lamp $\left(\mathrm{R}_{\mathrm{hs}}=7.77^{\circ} \mathrm{C} / \mathrm{W}\right)$ design example was performed considering some important standards to define the system features, as system efficacy, lifetime, total luminous flux, among others. For contemplating these requirements three main specifications were considered $\left(R_{h s}\right.$, $T_{j}$ and $E$ ) as functions of the LEDs' current and LEDs quantity. Experimental results prove the feasibility of the proposed methodology, through the analysis of the following specifications: luminous flux, luminous efficacy, and LED junction temperature. The errors between calculated and experimental values for these variables were $3.70 \%, 1.88 \%$, and $3.85 \%$, respectively.

Therefore, the proposed methodology facilitates the optimization and the previously definition of the desired features of lighting systems. Moreover, the design methodology provides time and energy savings, cost reductions due an optimized design, among others benefits. Thus, it is possible to define the minimum system requirements and to design the system with emphasis in the desired characteristics.

\section{REFERENCES}

[1] J. Cho, J. H. Park, J. K. Kim, E. F. Schubert, "White light-emitting diodes: History, progress, and future" in Laser \& photonics reviews, 2017.

[2] U.S. Department of Energy, "Solid-State Lighting R\&D Plan," DOE/EE-1228, May 2015.

[3] A. Poppe, C. J. M. Lasance, "On the standardization of thermal characterization of LEDs," in 25th Annual IEEE Semiconductor Thermal Measurement and Management Symposium, pp. 151-158, 2009.

[4] M. Arik, J. Petroski, S. Weaver, "Thermal challenges in the future generation solid state lighting applications: light emitting diodes," in The Eighth Intersociety Conference on Thermal and Thermomechanical Phenomena in Electronic Systems, pp. 113-120, 2002.

[5] E. F. Schubert. Light-Emitting Diodes, Cambridge University Press, Leiden, 2006.

[6] L.-R. Trevisanello, M. Meneghini, G. Mura, C. Sanna, S. Buso, G. Spiazzi, M. Vanzi, G. Meneghesso, and E. Zanoni, "Thermal stability analysis of high brightness LED during high temperature and electrical aging," in Seventh International Conference on Solid State Lighting, vol. 6669, no. 666913, 2007.

[7] H. Chen, S. Y. Hui, "Dynamic Prediction of Correlated Color Temperature and Color Rendering Index of Phosphor-Coated White Light-Emitting Diodes," IEEE
Transactions on Industrial Electronics, vol. 61, no. 2, pp. 784-797, Feb. 2014.

[8] H. T. Chen, Y. F. Cheung, H. W. Choi, S. C. Tan, and S. Y. Hui, "Reduction of Thermal Resistance and Optical Power Loss Using Thin-Film Light-Emitting Diode (LED) Structure," IEEE Transactions on Industrial Electronics, vol. 62, no. 11, pp. 6925-6933, Nov. 2015.

[9] C. Biber, "LED Light Emission as a Function of Thermal Conditions," in Twenty-fourth Annual IEEE Semiconductor Thermal Measurement and Management Symposium, pp. 180-184, 2008.

[10] V. C. Bender, O. Iaronka, W. Dotto Vizzotto, M. A. Dalla Costa, R. Nederson do Prado, and T. Bandeira Marchesan, "Design Methodology for Light-Emitting Diode Systems by Considering an Electrothermal Model," IEEE Transactions on Electron Devices, vol. 60, no. 11, pp. 3799-3806, Nov. 2013.

[11] S. Y. Hui, Y. X. Qin, "A General Photo-ElectroThermal Theory for Light Emitting Diode (LED) Systems," IEEE Transactions on Power Electronics, vol. 24, no. 8, pp. 1967-1976, Aug. 2009.

[12] H. T. Chen, X. H. Tao, S. Y. R. Hui, "Estimation of Optical Power and Heat-Dissipation Coefficient for the Photo-Electro-Thermal Theory for LED Systems," IEEE Transactions on Power Electronics, vol. 27, no. 4, pp. 2176-2183, Apr. 2012.

[13] L. Chies, M. A. Dalla Costa, V. C. Bender, "Improved design methodology for LED lamps" in IEEE 24th International Symposium on Industrial Electronics (ISIE), pp. 1196-1201, 2015.

[14] L. Chies, M. F. de Melo, W. D. Vizzotto, R. Spannemberg, V. C. Bender, M. A. Dalla Costa, "Design space for LED systems considering photoelectrothermal aspects", in IEEE Industrial Applications Society Annual Meeting, 2016.

[15] J. K. Kim, M.-H. Kim, M. F. Schubert, Q. Dai, T. Sakong, S. Yoon, C. Sone, Y. Park, J. Piprek, and E. F. Schubert, "The origin of efficiency droop in GaN-based light-emitting diodes and its solution," in Lasers and Electro-Optics and Conference on Quantum Electronics and Laser Science, pp. 1-2, 2008.

[16] Lumileds Holding B.V., "DS203 Luxeon 3535L 20150312", Technical Datasheet, Mar. 2015.

[17] D. Malacara. Color vision and colorimetry: theory and applications, SPIE, 2nd ed. Bellingham, 2011.

[18] D. S. Meyaard, J. Cho, E. Fred Schubert, S.-H. Han, M.-H. Kim, and C. Sone, "Analysis of the temperature dependence of the forward voltage characteristics of GaInN light-emitting diodes", Applied Physics Letters, vol. 103, no. 12, Sep. 2013.

[19] Critérios para a Concessão do Selo Proceliṣ̌. de Economia de Energia a șépíampadas LED com Dispositivo de Controle Integrado, Eletrobras, Ministério de Minas e Energia, 2015.

[20] ENERGY STAR $®$ Program Requirements for Lamps (Light Bulbs), U.S. Environmental Protection Agency, 2015.

[21] Portaria 389 Regulamento Técnico da Qualidade para Lâmpadas LED com Dispositivo de Controle Integrado 
à Base, Instituto Nacional de Metrologia, Qualidade e Tecnologia, Rio de Janeiro, 2014.

[22] Philips Lumileds Lighting Company, "IESNA LM-80 Test Report - LUXEON 3535L”, 2013.

[23] BRIDGELUX, "Effective Thermal Management of Bridgelux LED," Application Note, 2010.

[24] Illuminating Engineering Society of North America, IES approved method for the electrical and photometric measurements of solid-state lighting products, New York, 2008.

\section{BIOGRAPHIES}

Leandro Chies, born in Caxias do Sul, Brazil, in 1983. He received the B.S. degree in automation and control engineering from University of Caxias do Sul, in 2013 and M.Sc. degree in electrical engineering from the Federal University of Santa Maria, Brazil, in 2016. Since 2015 he is Professor at the Federal Institute of Santa Catarina, Brazil. His research interests include light-emittingdiode systems and image processing.

Maicol Flores de Melo, born in Cacequi, Brazil, in 1989. He received the B.S. and M.Sc. degrees in electrical engineering from the Federal University of Santa Maria, Santa Maria, in 2012 and 2014, respectively. Currently, he has been working toward the Ph.D. in the Gedre - Intelligence in Lighting research group. Since 2015 he is Professor at the Federal Institute Sul-rio-grandense, Brazil. His research interests include $\mathrm{dc} / \mathrm{dc}$ converters, power factor correction stages, lighting systems based on LEDs, renewable energy systems and integration of renewable energies and lighting systems.

William Dotto Vizzotto, born in 1993. He received the B.S. degree in electrical engineering from the Federal University of Santa Maria in 2017. He is researcher at Gedre Intelligence in Lighting research group since 2011. He has as main research topics: intelligence in lighting, DC-DC converters, LEDs, RGB LEDs, renewable energies and street lighting.

Rudimar Spannemberg Junior, born in Santa Maria, Brazil, in 1993. He is currently pursuing the Degree in electrical engineering at the Federal University of Santa
Maria. He have been carrying out the activities of research with the Gedre - Intelligence in Lighting research group since 2014. His main areas of interest are LEDs, LED drivers, street lighting, renewable energy and DC-DC converters.

Vitor Cristiano Bender, born in Panambi, Brazil, in 1987. He received the B.S. degree in Electrical Engineering from Regional Northwest University of Rio Grande do Sul State (UNIJUI) in 2011 and M.Sc. and PhD. degree from the Federal University of Santa Maria (UFSM) in 2012 and 2015, respectively. From 2015 to 2017 he was a professor at the Federal University of Pampa (UNIPAMPA). Currently, he is a professor in Federal University of Santa Maria where he has been working as researcher with GEDRE Intelligence in Lighting Research Group, at Santa Maria, Rio Grande do Sul, Brazil. His research interests include: lighting systems, electronic ballasts, LED and OLED drivers, LED and OLED modeling and thermal design.

Marco Antônio Dalla Costa, born in Santa Maria, Brazil, in 1978. He received the B.S. and M.Sc. degrees in electrical engineering from the Federal University of Santa Maria, Brazil, in 2002 and 2004, respectively, and the Ph.D. degree (with honors) in electrical engineering from the University of Oviedo, Gijón, Spain, in 2008. From 2008 to 2009 he was Associate Professor at the Universidade de Caxias do Sul, Brazil. Since 2009 he is Professor at the Federal University of Santa Maria, Brazil. Dr. Dalla Costa is coauthor of more than 50 journal papers and more than 100 international conference papers, and is holder of 2 Spanish patents. He is also the Vice-Chair of the Industrial Lighting and Displays Committee (ILDC) from the IEEE Industry Applications Society and serves as reviewer for several IEEE Journal and Conferences in the field of power electronics. His research interests include $\mathrm{dc} / \mathrm{dc}$ converters, power factor correction, lighting systems, high-frequency electronic ballasts, discharge-lamp modeling, light-emitting-diode systems, renewable energy systems, solid state transformers, and visible light communications. 